\title{
Evaluating safety of drinking water using animal cell bioassays
}

\author{
G. K. Luk \\ Department of Civil Engineering, Ryerson University, \\ Toronto, Ontario, Canada
}

\begin{abstract}
Disinfection byproducts (DBPs) such as trihalomethanes (THMs), haloacetic acids (HAAs), 3-chloro-4-(dichloromethyl)-5-hydroxyl-2(5H)-furanone (MX) and other hazardous compounds are produced by chlorination of raw water in the water treatment plants. Most chlorinated by-products are formed by the interaction of chlorine and natural organic matter (NOM) such as fulvic and humic acids, which are present in most surface waters. Many of these byproducts are suspected to be mutagenic or carcinogenic in nature. The objective of the paper is to demonstrate the effectiveness of bioassay-directed research in evaluating the safety of chlorinated drinking water, and to investigate the effect of $\mathrm{pH}$ on the genotoxicity of chlorinated sample water.
\end{abstract}

Keywords: disinfection byproducts, chlorination, drinking water, bioassays.

\section{Introduction}

Although water disinfection has been quite successful in eliminating many acute waterborne diseases in the developed world, many potential health hazards related to disinfection by-products (DBPs) have been reported $[1,2]$. Epidemiological studies demonstrate that many potential health risks such as cancers of the stomach, pancreas, kidney, bladder, and rectum, as well as Hodgkin's and non-Hodgkin's lymphoma have been linked to exposure to DBPs [3]. DBPs such as trihalomethanes (THMs), haloacetic acids (HAAs), 3chloro-4-(dichloromethyl)-5-hydroxyl-2 $(5 \mathrm{H})$-furanone (MX) and other hazardous compounds are produced by chlorination and other disinfection methods of raw water in the water treatment plants. Most chlorinated byproducts are formed by the interaction of chlorine and natural organic matter 
(NOM) such as fulvic and humic acids, which are present in most surface waters [4]. The problem is intensified with the presence of bromine which can be found in most natural waters. Many of these by-products are suspected to be mutagenic or carcinogenic in nature $[5,6]$.

The purpose of this study is to demonstrate the effectiveness of bioassaybased research for the investigation of genotoxic potential of chlorinated water. Past studies on bioassay-directed research has confirmed many advantages over traditional clinical studies involving lab animals, resulting in tremendous saving in time and cost. For instance, it has been found through bioassays that the mutagenicity of chlorinated water is dependent on $\mathrm{pH}$ and temperature [7-10], albeit the nature of dependency over a wide range of $\mathrm{pH}$ has not been studied in detail. The objective of this paper is to evaluate the genotoxicity of total organic halides (TOXs) produced by the reaction of chlorine and NOM, in the form of humic acid, under different raw water $\mathrm{pH}$ conditions. As a measure of genotoxicity, the in vitro bioassay test measuring chromosomal aberrations using Chinese hamster lung (CHL/IU) cells was carried out, and was used as an index to examine the change of activity inducing chromosomal aberrations after chlorination of water samples containing humic acid.

\section{Health effects and regulations of DBPs}

Since the discovery of chlorinating byproducts in drinking water in 1974, numerous toxicological studies have been conducted. These studies have shown several disinfection byproducts, such as bromate, certain trihalomethanes (THMs) and haloacetic acids (HAAs), to be carcinogenic in laboratory animals. Other disinfection byproducts including chlorite, certain THMs and HAAs have also been shown to cause adverse reproductive or developmental effects in laboratory animals. However, there is considerable uncertainty involved the results of high-dose, toxicological studies of some byproducts occurring in disinfected drinking water to estimate the risk to humans from chronic exposure to low doses of these and other byproducts.

In the area of epidemiology, a number of studies have been completed investigating the relationship between exposure to chlorinated surface water and cancer. Even though the results are not complete, the US-EPA [11] established that based on available evidence, there is a causal link between exposure to chlorinated surface water and cancer, and that these studies have suggested an association, albeit small, between bladder, rectal, and colon cancer and exposure to chlorinated surface water. In conclusion, the US-EPA believes the weight-ofevidence presented by the available epidemiological studies on chlorinated drinking water and toxicological studies on individual disinfection byproducts supports a potential hazard concern and warrant regulatory action. In January 2006, the U.S. EPA published the Stage 2 Disinfectants/Disinfection Byproducts Rule [12] that requires public water systems to use treatment methods to reduce the formation of disinfection byproducts and to meet the following standards, among others: total trihalomethanes (TTHM) (measured as the sum concentration of chloroform, bromoform, bromodichloromethane, and 
dibromochloromethane) at 80 parts per billion (ppb), five haloacetic acids (HAA5) (measured as the sum concentration of monochloroacetic, dichloroacetic, trichloroacetic, monobromoacetic, and dibromoacetic acids) at 60 $\mathrm{ppb}$, bromate at $10 \mathrm{ppb}$, and chlorite at 1.0 parts per million (ppm). The standards for TTHM, HAA5, and bromate are annual averages. For chlorite, the standard is an average of a three samples taken at least monthly.

\section{In vitro chromosome aberration assays}

The past century has been witness to enormous advances in the study of genetic toxicity, which focuses on the processes of mutagenesis, including the induction of DNA damage, gene mutation and chromosome aberration, at the cell level. These genotoxic effects are considered important precursors to the development of adverse health effects such as cancer. As important primary screening tools for the assessment of genetic hazard, genetic toxicity test systems are categorised by the end points that they measure, such as gene mutation, chromosome damage or DNA damage [13]. The strong association between these end points and known mechanisms of oncogeny activation or loss of tumour suppressor gene function places great importance on genotoxicity testing to evaluate the mutagenic and carcinogenic potential of consumer and industrial products, pharmaceutical and agricultural agents, and environmental samples.

The chromosome aberration assay provides a technique for evaluation of damage to chromosomes through direct visualization of the damage caused by the test article under investigation. The purpose of this test is to identify agents that cause chromosome aberrations in cultured mammalian cells, as well as to screen populations for chromosome anomalies arising as a result of environmental agents. More specifically, Putman et al [13] stated that the aim of the in vitro cytogenetics assay is to evaluate the clastogenic or chromosome breakage potential of a test contaminant and its metabolites based upon their ability to induce chromosome aberrations in a culture. The use of cell cultures as a test system has been demonstrated to be an effective method of detection of chemical clastogens and the induction of chromosome breakage in vitro is an indication that the test article is potentially genotoxic [14]. The chromosomal aberration assay is vital because there is strong evidence to suggest that chromosome mutations and related events cause alterations in the oncogenes and tumour suppressor genes of somatic cells and are involved in cancer induction in humans and animals [15].

\subsection{Chromosomal aberrations}

Two types of chromosomal abnormalities can be detected using the in vitro chromosome aberration assay: structural chromosome aberrations and numerical chromosome aberrations. Structural aberrations include deviations such as breaks and rearrangements and can result in a discontinuity in the chromosomal DNA. These discontinuities may be repaired, rejoined inappropriately, or left unrejoined, causing a break or a deletion in the chromosome [13]. Structural 
aberrations may be of two types, chromosome or chromatid. Chromosome-type aberrations are expressed as a breakage or a breakage and reunion of both chromatids at an identical site. The majority of chemical mutagen induced aberrations are chromatid type, in which structural chromosome damage is expressed as breakage of single chromatids or breakage and reunion between chromatids [16], as shown in fig. 1.

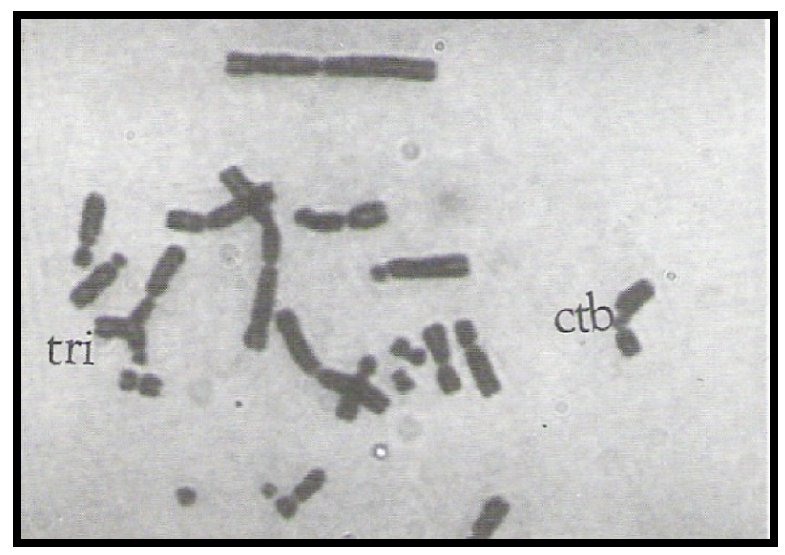

Figure 1: Chromatid type structural aberrations in Chinese hamster ovary (CHO) chromosomes; chromatid break (ctb) and triradial chromatid rearrangement (tri).

For the most part, structural aberrations are lethal to the cell or to the daughter cells in the first few cell cycles after their appearance. However, these structural deviations may also serve as an indicator of the occurrence of transmittable aberrations, such as balanced translocations, duplications, inversions or small deletions, and may play a role in tumor initiation and progression in somatic cells [15].

On the other hand, numerical aberrations are variations in the number of chromosomes in the nucleus from the normal number characteristic of the cell. Studies have generally found that numerical chromosome aberrations are not due to the direct interaction of an environmental agent with the chromosomal DNA [13]. Although numerical aberrations do not seem to play a key role in the initiation of tumours and the physiological and genotoxic impacts of polyploidy and endoreduplication are less than clear, they may be indicative of the evolution of karyotypic instability within a population of tumour cells. The in vitro cytogenetics assay was not designed to measure numerical aberrations and is not routinely used for that purpose.

\subsection{Cell selection}

The chromosome aberration test system can be run using either established cell lines or primary cell cultures. The cell lines routinely used in this assay are 
Chinese hamster ovary (CHO) cells and Chinese hamster lung (CHL) cells grown in mono-layer cultures, as shown in fig. 2. There are a number of advantages to using established cell lines from frozen stocks. Cell lines are genetically more homogeneous than primary cell cultures and thus tend to show less inter-experimental variability within the cell types [13]. Secondly, the established Chinese hamster cell lines are advantageous for use in the in vitro cytogenetics assay because they are easily cultured in standard media, have a small number of large chromosomes each with a more or less distinctive morphology, and have a relatively short cell cycle [17]. On the other hand, primary cell cultures, such as human peripheral blood lymphocytes (HPBL), show some variability among donors in their response and sensitivity to test articles compared to established cell lines [18], but the relevance of these systems to human exposure to test articles cannot be overlooked.

JCRB0030 : CHL/IU (06042002)
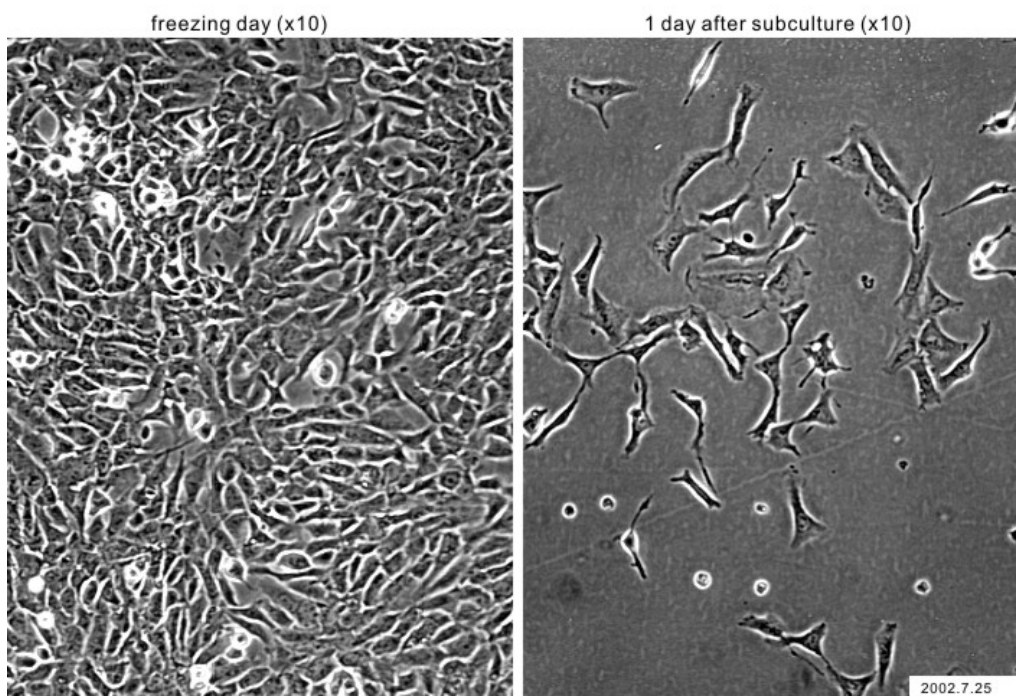

Figure 2: $\quad$ Cultured CHL metaphase with 100x magnification.

During cell culturing, treatment and preparation of samples for mounting, there is extensive chromosome rearrangement and it is an inherent property of most established cell lines that the chromosome number varies around a modal value [18]. As such, it is necessary to establish criteria for defining analyzable cells; current criteria are that cells with the modal chromosome number \pm 2 chromosomes are acceptable for microscopic analysis [13]. For CHL cells, which have a modal chromosome number of 25 , all cells with chromosome numbers ranging from 23 to 27 are considered as acceptable samples for the reading. This criterion has been adopted for the present study.

Prior to the start of the assay, frozen stocks should be established and cells checked for contamination by parasitic, pathogenic microorganisms, such as 
mycoplasma [19]. Since the objective of the chromosome aberration assay is to determine whether test chemicals induce aberrations in a culture, environmental factors, such as $\mathrm{pH}$, cytotoxicity and osmolality, must be carefully monitored and adjusted to physiological levels if necessary, as extremes of these factors can cause chromosome aberrations [13]. As there are natural background levels of mutation, a negative control test is also required to assess the relative increases in the measured end-point, in this case structural or numerical aberrations. It is necessary to determine how many aberrations occur in the control (untreated or solvent control) sample, and subtract that base number from all of the test samples.

\section{Experimental design}

The chromosome aberration assay was conducted in two stages: the preliminary toxicity assay and the chromosome aberration assay. The preliminary toxicity assay served as a dose range-finding assay for the definitive portion of the study. There are a number of protocols in place for determining which exposure concentrations should be tested in order to ensure that concentrations cover the range from the maximum to little or no toxicity (e.g. $>50 \%$ reduction in cell growth or confluency) $[13,16]$. In cases where the contaminant in question is wide-spread in the environment, either from long-time human use or disposal practices, it may be possible to use a dose range that reflects the concentrations of the chemical found in natural systems. This was the method used in this study, in which both chlorination level and concentration of humic acid were predetermined to reflect worst-case values in real life. In the chromosome aberration assay, the clastogenic potential of the contaminant is evaluated microscopically. After cells are exposed to the test substance for $24 \mathrm{~h}$, they are treated with a metaphase-arresting substance, harvested, stained and examined microscopically. As shown in fig. 3 , the cells are first inspected with a magnification of $400 \mathrm{x}$ for identification, and further magnified with a minimum magnification of $1000 \mathrm{x}$ for the presence of both numerical and structural aberrations.

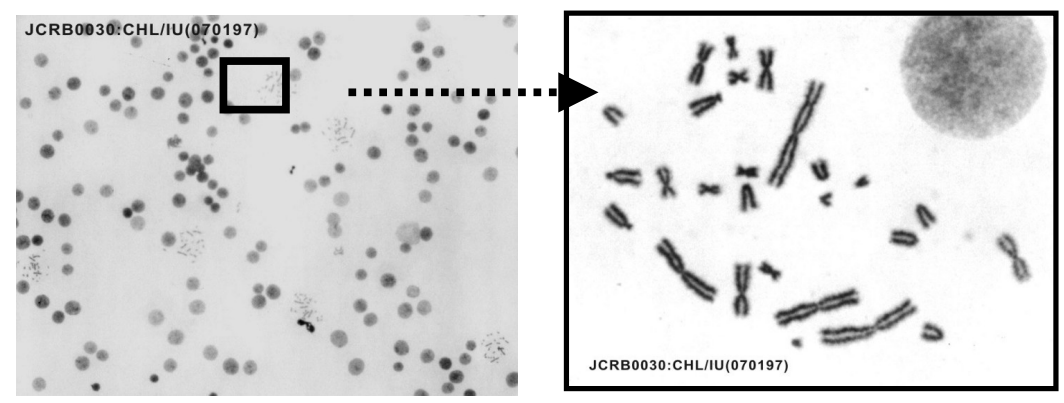

Figure 3: $\quad$ Views of slide at 400x (left) and 1000x (right) magnification.

The chromosomal aberration test was carried out on a Chinese hamster lung (CHL/IU) cell-line supplied by Dainihon Pharmaceutical Co. Ltd., and cultured 
at $37^{\circ} \mathrm{C}$ in a $5 \% \mathrm{CO}_{2}$ incubator. The cells are kept in $50 \mathrm{~mL}$ disposable ventible culture bottles with $10-11 \mathrm{~mL}$ of Eagle's MEM medium supplemented with $10 \%$ fetal bovine serum. Mutagenesis assays were performed in duplicates, and 100 metaphase cells were analysed for structural aberration from each duplicate. To assess the activity-inducing chromosomal aberrations in the cells, a 1-mL study sample was added to a 1-day-old CHL culture containing $1 \mathrm{~mL}$ of cell mixture and $5 \mathrm{~mL}$ of MEM media, and incubated for 24 hours. Bacteria in the samples were eliminated prior to addition with a sterile syringe-driven $0.22 \mu \mathrm{m}$ filter unit (Millex ${ }^{\circledR}-F G$ SLFG 025 LS). Chromosome preparations were fixed on microscopic slides with a fixation solution made of a $3: 1 \mathrm{v} / \mathrm{v}$ methanol and glacial acetic acid (with $>96 \%$ purity), and stained with a $1.5 \%$ Giemsa solution prepared with a phosphate buffer at $\mathrm{pH}$ 6.8. Bioassays were carried out for samples at a $\mathrm{pH}$ of 5,7 , and 9 respectively, and covering a chlorine concentration range of 0 to $1500 \mathrm{mg} \mathrm{Cl} / \mathrm{L}$.

\section{Results and discussion}

The experimental results are summarized in fig. 4. It was observed that chromosomal aberrations increase almost linearly with increasing chlorine concentration. It can also be observed that the amount of $\mathrm{TOCl}$ decreased by $70 \%$ when $\mathrm{pH}$ was increased from 5 to 9 , at a chlorination level of $\{\mathrm{HOCl}\}=$ $1,500 \mathrm{mg} \mathrm{Cl} / 2$. In spite of this, there did not seem to be any noticeable difference in the activity inducing chromosomal aberrations with $\mathrm{pH}$ change.
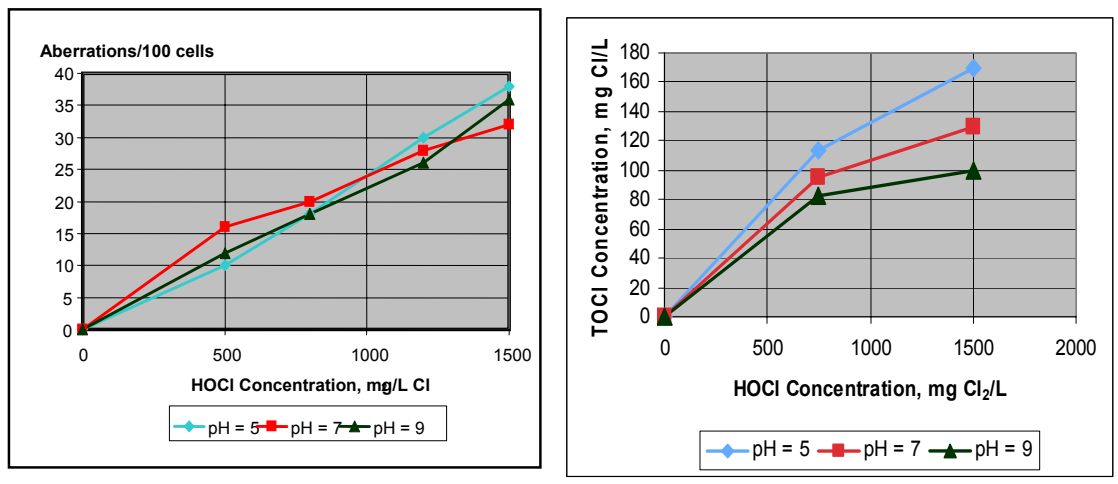

Figure 4: Bioassay (left) and analytical results.

When a reasonable margin of error for the chromosomal aberration test (+/$10 \%$ ) was considered, the bioassay data taken from samples with three different $\mathrm{pHs}$ falls practically on the same linear trend, and the best-fit linear regression equation is given by:

$$
\mathrm{N}=0.0236\{\mathrm{HOCl}\} \quad\left(\mathrm{R}^{2}=0.9779\right)
$$

where $\mathrm{N}$ is the number of activity inducing chromosomal aberrations per 100 cells, and $\{\mathrm{HOCl}\}$ is the concentration of $\mathrm{HOCl}$ in $\mathrm{mg} \mathrm{Cl} / \mathrm{L}$. To investigate the 
reasons behind this peculiar observation, it is necessary to evaluate the aberration initiation strength, defined as the number of chromosomal aberrations per $\mathrm{mg}$ $\mathrm{Cl} / \mathrm{L}$ of $\mathrm{TOCl}$, and given by the following equation:

$$
\mathrm{A}_{\mathrm{TOCl}}=\frac{\mathrm{N}}{\{\mathrm{TOCl}\}} \bullet \mathrm{DF}
$$

where $\mathrm{N}$ is the number of chromosomal aberrations per 100 cells, $\{\mathrm{TOCl}\}$ is the concentration of $\mathrm{TOCl}$ in $\mathrm{mg} \mathrm{Cl} / \mathrm{L}$, and $\mathrm{DF}$ is the dilution factor for the sample during the bioassay experiments. According to the standard chromosomal aberration test procedure, a $1-\mathrm{mL}$ sample is added to $1 \mathrm{~mL}$ of cell mixture submerged in $5 \mathrm{~mL}$ of MEM cell growth medium, giving a total volume of $7 \mathrm{~mL}$. Therefore, the dilution factor of the sample is 7 for all tests. When the $\mathrm{A}_{\mathrm{TOCl}}$ values were evaluated and averaged for each $\mathrm{pH}$, as shown in table 1 , it can be observed that the aberration initiation strength increased by $49.6 \%$, from 1.25 to 1.87 aberrations per $\mathrm{mg} \mathrm{Cl} / \mathrm{L}$, when the $\mathrm{pH}$ was changed from 5 to 9 . Therefore, it can be concluded that while the amount of $\mathrm{TOCl}$ decreases when $\mathrm{pH}$ is increased, the aberration initiation strength increases, thus creating a "compensation effect" which results in no discernable difference in genotoxicity with $\mathrm{pH}$.

Table 1: $\quad$ Aberration per unit $\mathrm{TOCl}$ at different $\mathrm{pH}$ values.

\begin{tabular}{ccccc}
\hline $\mathbf{p H}$ & $\begin{array}{c}\text { Chlorination } \\
\left(\mathbf{m g ~ C l}_{\mathbf{2}} / \mathbf{L}\right)\end{array}$ & $\begin{array}{c}\text { Aberrations } \\
\text { per } \mathbf{1 0 0} \text { cells }\end{array}$ & $\begin{array}{c}\text { TOCl } \\
(\mathbf{m g ~ C l} / \mathbf{L})\end{array}$ & $\begin{array}{c}\mathbf{A}_{\text {TOCl }} \\
(\mathbf{p e r} \mathbf{~ m g ~ C l} / \mathbf{L})\end{array}$ \\
\hline 5.0 & 500 & 10 & 76 & 0.132 \\
& 800 & 18 & 118 & 0.153 \\
& 1200 & 30 & 147 & 0.204 \\
& 1500 & 38 & 170 & 0.224 \\
& & & & Avg. $=1.25$ \\
\hline 7.0 & 250 & 5 & 53 & 0.094 \\
& 500 & 8 & 62 & 0.129 \\
& 750 & 10 & 92 & 0.108 \\
& 1000 & 11 & 95 & 0.116 \\
& 1250 & 15 & 151 & 0.099 \\
& 1500 & 16 & 140 & 0.115 \\
& & & & Avg. $=1.54$ \\
\hline 9.0 & 500 & 12 & 55 & 0.218 \\
& 1200 & 18 & 84 & 0.214 \\
& 1200 & 26 & 95 & 0.274 \\
& 1500 & 36 & 100 & 0.360 \\
& & & & Avg. $=1.87$ \\
\hline
\end{tabular}

It should be noted that although the in vitro chromosome aberration assay is an important tool for screening potential mutagens and carcinogens, it does not 
give a perfect correlation between the results and carcinogenicity. It has been documented that a test chemical for which there is a negative result, indicating that the test chemical does not induce aberrations, may still be a carcinogen, since carcinogens may act through mechanisms other than direct DNA damage $[15,16]$. Despite these potential limitations, the chromosome aberration assay provides two distinct advantages. First, the test is very useful for comparisons of chemicals in the same class and provides a direct measure of their relative toxicity. Secondly, the test is not financially prohibitive and is feasible even for smaller laboratories. The test does not require the use of laboratory animals or the space to house and care for them; there are fewer requirements for additional staff (animal care technicians, etc.) and/or training, and equipment.

\section{Conclusions}

Based on the results from in this study, it is concluded that while genotoxicity increases with increasing chlorination, the effect of $\mathrm{pH}$ on genotoxicity is not significant owing to the compensation effect of the aberration initiation strength. The study also demonstrated that in vitro chromosome aberration assay provides an excellent opportunity to quickly and efficiently test a large number of potential genotoxins, under a wide range of conditions. This in turn allows for the prioritization of further research through laboratory or clinical trials.

\section{References}

[1] Richardson, S.D., Drinking water disinfection by-products. Encyclopedia of Environmental Analysis and Remediation, ed. R.A. Meyers, John Wiley \& Sons, pp. 1398-1421, 1988.

[2] Bull, R.J. Drinking water disinfection. Environmental toxicants: human exposures and their health effects, ed. M. Lippmann, John Wiley \& Sons, pp. 267-317, 2000.

[3] Nieuwenhuijsen, M.J., Toledano, M.B., \& Elliott P., Uptake of chlorination disinfection by-products: a review and a discussion of its implications for exposure assessment in epidemiological studies. J. Expos. Analy. Environ. Epidem., 10, pp. 586-599, 2000.

[4] Weinberg, H.S., Krasner, S.W., Richardson, S.D. \& Thurston, A.D. Jr. The Occurrence of Disinfection By-products (DBPs) of Health Concern in Drinking Water: Results of a Nationwide DBP Occurrence Study, National Exposure Research Laboratory, US Environmental Protection Agency, 2002.

[5] Wilcox, P. \& Williamson, S., Mutagenic activity of concentrated drinking water samples. Environ. Health Perspect., 69, pp. 141-149, 1986.

[6] Plewa, M.J., Wagner, E.D., Jazwierska, P., Richarson, S.D., Chen, P.H. \& McKague, A.B., Halonitromethane drinking water disinfection byproducts: chemical characterization and mammalian cell cytotoxicity and genotoxicity. Env. Sc. \& Tech., 38, pp. 62-68, 2004. 
[7] Meier, J.R., Lingg, R.D. \& Bull, R.J., Formation of mutagens following chlorination of humic acid: a model for mutagen formation during water treatment. Mutat. Res., 118, pp. 15-41, 1983.

[8] Fukui, S., Yoshimura, Y., Ogawa, S. \& Hanazaki, Y., Formation of nonvolatile potent mutagens in domestic sewage by chlorination. Chemosphere, 21(6), pp. 705-716, 1990.

[9] Itoh, S., Murakami, H. \& Sumitomo, H., Activities inducing chromosomal aberrations of waters treated with disinfectants and the stability of them. Proc. IWSA Specialized Conference on Advanced Treatment and Integrated Water Systems Management into the $21^{\text {st }}$ Century, Osaka, Japan, Vol. 1:134-139, 1995.

[10] Kamaguchi, H., Behaviour of disinfection by-products by $\mathrm{pH}$ adjustment of drinking water", J. Water Waste, 38(12), pp. 20-26, 1996 (in Japanese).

[11] National Research Council. Drinking Water and Health: Disinfectants and Disinfectant By-Products, Vol. 7, National Academy Press, Washington D.C., 1987.

[12] U.S. Environmental Protection Agency. Stage 2 Disinfectants and Disinfection By-Products Rule, Vol. 71, No. 2, Ref. 71FR388, 2006. www.epa.gov/safewater/disinfection/stage 2/

[13] Putman, D.L., Gudi, R., Wagner III, V.O., San, R.H.C. \& Jacobson-Kram, D., Genetic toxicology. Toxicology Testing Handbook: Principles, Applications, and Data Interpretation, eds. D. Jacobson-Kram \& K.A. Keller. Marcel Dekker, Inc.: New York, pp. 127-194, 2001.

[14] Preston, R.J., Au, W., Bender, M.A., Brewen, J.G., Carrano, A.V., Heddle, J.A., McFee, A.F., Wolff, S. \& Wassom, J.S., Mammalian in vivo and in vitro cytogenetic assays: a report of the U.S. EPA's Gene-Tox program. Mutation Research, 87, pp. 143, 1981.

[15] Tlsty, T.D., Briot, A., Gualberto, A., Hall, I., Hess, S., Hixon, M., Kuppuswamy, D., Romanov, S., Sage, M. \& White, A., Genomic instability and cancer. Mutation Research, 337:1, 1995.

[16] OECD, In vitro mammalian chromosome aberration test. Guideline for the Testing of Chemicals, OECD Press, 473, 1997.

[17] Ishidate, M., Harnois, M.C. \& Sofuni, T., A comparative analysis of data on the clastogenicity of 951 chemical substances tested in mammalian cultures. Mutation Research, 195, pp. 151, 1988.

[18] Kirkland, D., Chromosomal aberration tests in vitro: problems with protocol design and interpretation of results. Mutagenesis, 7, pp. 95, 1992.

[19] International Conference on Harmonisation (ICH), Technical requirements for registration of pharmaceuticals for human use. Genotoxicity: A Standard Battery for Genotoxicity Testing of Pharmaceuticals, 1997. 